\title{
Increasing student engagement through virtual interactions: How?
}

\author{
Athanasios Christopoulos $^{1}\left[\right.$. Marc Conrad ${ }^{1} \cdot$ Mitul Shukla $^{1}$ \\ Received: 26 October 2016 / Accepted: 18 December 2017 / Published online: 5 January 2018 \\ (c) The Author(s) 2018. This article is an open access publication
}

\begin{abstract}
Our ongoing research is focusing on identifying and taxonomising the elements and the factors that affect learner engagement with virtual worlds when hybrid virtual learning models are used. Our main hypothesis links learner engagement with interactions, both in the virtual world and in the physical classroom. In order to examine this subject, there is an elaboration on and consideration of aspects such as the learners' prior experiences in the use of virtual worlds, their preconceptions about using them as a learning tool and the impact that the instructional designers' choices have on enhancing the opportunities for interactions. In this paper, we examine the impact that the orientation process has on university students who study computer science and have almost no experience in the use of virtual worlds. Our findings suggest that the orientation process contributed positively to students' smooth induction and that resulted in having meaningful and engaging interactions. Furthermore, students' simultaneous coexistence in both environments eliminated the drawbacks of each educational approach and broadened the network of interactions.
\end{abstract}

Keywords Architectures for educational technology systems · Collaborative learning · Improving classroom teaching · Interactive learning environments · Virtual reality

\section{Introduction}

Despite the fact that virtual worlds were primarily introduced as computer-aided 2D or 3D artificial environments (Bainbridge 2007; Dickey 2005) aiming to cover leisure needs (Bartle 2003), within the last decade they have massively progressed and served various purposes such as socialisation, recreation, exploration, collaboration and education (Begg et al. 2005; Hockey et al. 2010). The unique features that virtual worlds like Second Life (http://secondli fe.com/) or OpenSimulator (http://opensimulator.org/wiki/ Main_Page) have attracted researchers' and educators' interest leading them to explore their capabilities and potential in teaching and learning. However, a large portion of the active research relates to virtual worlds is focusing on their 'inside'

Athanasios Christopoulos

athanasios.christopoulos@beds.ac.uk

Marc Conrad

marc.conrad@beds.ac.uk

Mitul Shukla

mitul.shukla@beds.ac.uk

1 School of Computer Science and Technology, University of Bedfordshire, Park Square, Luton LU1 3JU, UK perspective disregarding partially or even completely the 'real world' (Bredl et al. 2012; Childs 2010; Miller et al. 2010; Vosinakis et al. 2011). The outcome of these studies is considerably useful in e-learning or distance learning scenarios (Dickey 2005; Hockey et al. 2010; Minocha and Tingle 2008); however, the importance of the concurrent consideration of both an 'intrinsic' and an 'extrinsic' view of virtual worlds has been highlighted by Shukla and Con$\operatorname{rad}(2011)$. The idea of examining virtual worlds from both perspectives led to the invention of a new terminology, the so-called blended or hybrid virtual learning. Even though Khan and Lindquist (2002) claim that this term is fairly new, Akkoyunlu and Y1lmaz-Soylu (2008) report that its idea has existed for decades. Several definitions have been given to this term describing it as a mixed-reality environment where the physical and the virtual world are linked through interactions (Bower et al. 2010; Hoshi et al. 2009; Sharpe et al. 2006; Singh et al. 2001; Williams 2002). We completely concur with this term, and our study aims to identify the synergies between instructional design and learner choices, whereas interactions constitute the medium to achieve greater levels of learner engagement with the virtual world and, by extension, with the educational material. 


\section{Literature review}

Schrader (2008) has identified four different combinations that link technology and learning, which are namely: 'learning about technology', 'learning from technology', 'learning with technology' and 'learning in technology'. Virtual worlds provide the necessary context for different types of interactions either between the users and the content of the world or the users themselves. Typical examples of these types of interactions are the object creation (Allison et al. 2012; Dalgarno and Lee 2010) and manipulation (Bredl et al. 2012; Dalgarno and Lee 2010;), terrain editing (Allison et al. 2012) and navigating around the world (Herbet et al. 2012; Hockey et al. 2010; Johnson et al. 2009). Communication is, indeed, another important factor which increases the opportunities for interaction between the users; be it synchronous or asynchronous, verbal or written (chat) or through the use of avatar gestures (Carter 2012; Hockey et al. 2010; Johnson et al. 2009). Virtual worlds have been used in various paradigms as they provide fertile ground for the implementation of different learning styles, e.g. problem-based learning, exploratory learning and distance learning (Christopoulos 2013). Vygotsky's (1978) Social constructivist learning theory has great practical application in virtual worlds since it covers issues such as the fact that students become active learners whilst developing their cognitive structures and knowledge through the complex network of interactions that motivate them to engage with the virtual world and the learning material. Indeed, as Jones (2011) suggests, learners have the ability to actively affect, alter and enhance the content of the virtual world in a manner that will enable them to construct their cognitive schemes and engage with the subject they study. Zhao et al. (2010) further extend the aforementioned claim and also suggest that learning becomes more self-directed and student centred, whereas educators get the role of instructional designers or supporters of activities that aim to engage students in learning (Anasol et al. 2012; Schrader 2008).

Educators' 'new' role has triggered the conduct of several studies focusing on the interactivity of the virtual worlds and the in-world interactions that can-or need to-be developed in order to cover students' learning needs. Some studies investigate the use of virtual worlds in distance learning scenarios (de Freitas et al. 2009) aiming to identify an evaluation method to measure students' learning experiences, whilst others cover the skills students acquire when they start using virtual worlds (Childs 2010). Another group of studies focuses on the elements that affect a virtual world's interactivity (Steuer 1992), whereas others attempted to address the aforementioned topic from a different perspective (Chafer and Childs
2008) as they identified additional parameters. However, most of these studies disregard the perspective of learning in the physical classroom in conjunction with the virtual world (Camilleri et al. 2013).

Based on the review of the literature that we have conducted, only a few studies attempted to examine interactions both from the inside and from the outside. Levesque and Lelievre (2011) suggest that great emphasis should be given on the enhancement of interactions both in the virtual world and in the physical classroom when hybrid virtual learning (HVL) approaches are to be used. de Freitas et al. (2010) also underline the importance and need for further investigation of the potential and the affordances of hybrid spaces with simultaneous student physical and virtual presence. Other researchers (Elliott et al. 2012) highlight the lack of detailed taxonomy of all the interactions related to the educational use of virtual worlds, which would aid in a better understanding of their affordances, in a more expedient design of educational activities and in a more thorough exploitation of their potential.

\section{Problem statement and hypothesis}

Educators often face problems of learner engagement with the learning material. The main idea of this study is that interactions in virtual worlds, which have been modified in order to cover educational needs, can enhance the levels of learner engagement. That said, the more interactive the virtual world is, the higher levels of engagement with the learning activities learners can reach. Respectively, the interactions related to the use of a virtual world that take place in the physical classroom can assist greatly in achieving that goal. In HVL models, students are co-present and interacting simultaneously both within the virtual world and the physical classroom receiving stimuli related to the learning material in the virtual world from both directions. Thus, the main hypothesis of this study is: Do HVL models result in higher levels of engagement with the virtual world and, by extension, the learning subject?

\section{Research methods and design}

In order to cover the needs of this study, two research methods were used: observations and surveys (Cohen et al. 2011). The use of both qualitative and quantitative methods aids validity and diversity, gives a more thorough view of the phenomena and allows for the triangulation of primary data. In other words, observations were used to record student actions and behaviour (in-class/in-world), whilst surveys were used to record preferences (Fig. 1). As far as the chronological order is concerned, students were asked to fill 
Fig. 1 Data collection process

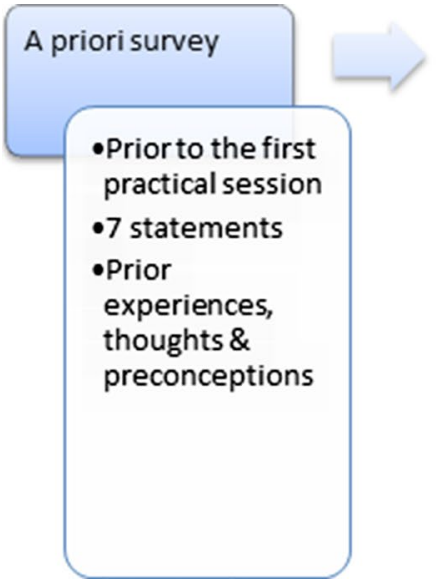

in a brief questionnaire (a priori survey) prior to using the virtual world for first time, whereas the observations were being held in the physical classroom during the conduct of each sub-experiment. Finally, the a posteriori survey was distributed to students after the completion of their assignment. In this paper, we will examine the findings derived from the survey study.

\subsection{Surveys}

The main reason which led us to use surveys was the fact that not all the students could take part in the observations. Therefore, the data gathered from the surveys were thought to be used supplementary to those gathered from observations, since these would reveal students' thoughts about the use of the virtual world and justify their actions and behaviours. Moreover, they allow researchers to collect large-scale data and perform statistical analysis leading to stronger and more accurate generalisations. Finally, they are thought to be participant friendly, since it is widely used, and participants are familiar with it.

\subsection{The pedagogical observation method}

What is considered to be the most essential advantage of observation is the principles of 'immediate awareness' and 'direct cognition'-i.e. the opportunity given to a researcher to have a 'direct look' at the actions that take place without having to rely on second-hand accounts-as described in (Cohen et al. 2011) that lead to the emergence of unique primary data. Secondly, it is a very flexible form of data collection that allows researchers to alter their focus, depending on the observed actions and behaviours. Finally, the method of observation allows the researcher to gather any necessary data, whilst the participants unimpeded follow their own agenda and priorities. At this point, it should be mentioned that all the authors were present in the classroom, where the observations were taking place, even though only one
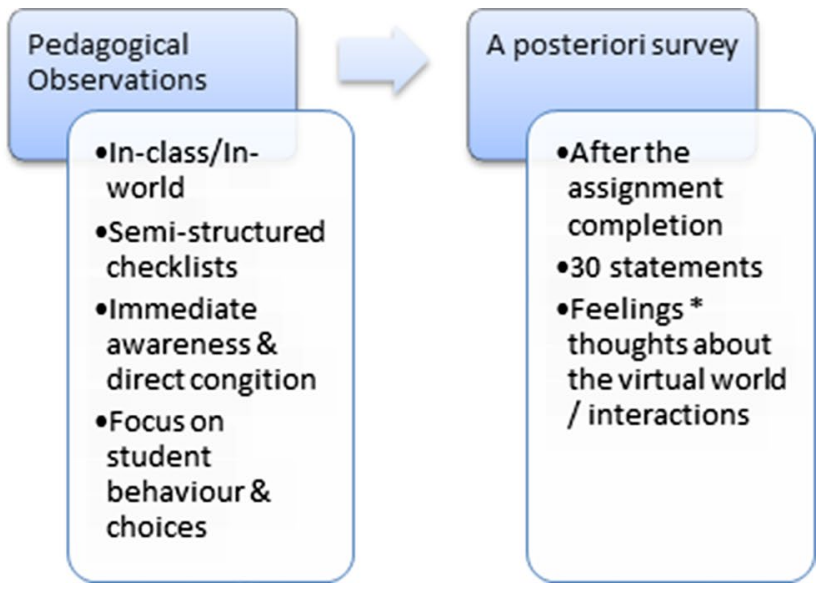

of them was observing, monitoring and recording (using an observation checklist) students' behaviour.

\section{Experiment design}

For this experiment, the OpenSimulator architecture was chosen because of its open source nature, the ability to host and control it within the university environment and the considerable low cost to maintain (Christopoulos 2013). Within the orientation area, students could explore and familiarise themselves with the in-world tools, acquire information about the avatars' appearance editing process (including outfits as freebies), socialise and rest away from their workspaces. Outside the orientation 'school', a meeting place has been set up to enable students socialise or rest away from their workspaces. In addition, there was a sandbox area with instructions about the in-world scripting language, as well as the 3D object design and manipulation process. Figures 2 and 3 illustrate the design of the orientation area and its surroundings.

In both surveys, participation was voluntary with the sample consisting of the same cohort of students. The a priori survey consisted of 7 statements covering personal details, prior exposure and preconceptions to virtual worlds. The a posteriori survey consisted of 21 statements on a five-point Likert scale and an open-ended question at the end. The first part (11 statements) examined students' in-world interactions with the content of the world and the second part (10 statements) with other users. In the open-ended question, participants were asked to indicate the factors that would have helped them become more engaged.

This paper focuses on the impact that the orientation (induction) process has on students' actions, interactions and engagement from the students' perspective (surveys). The findings derived from the observations are discussed in Christopoulos et al. (2017). Figure 4 illustrates the set-up of the experiments. 

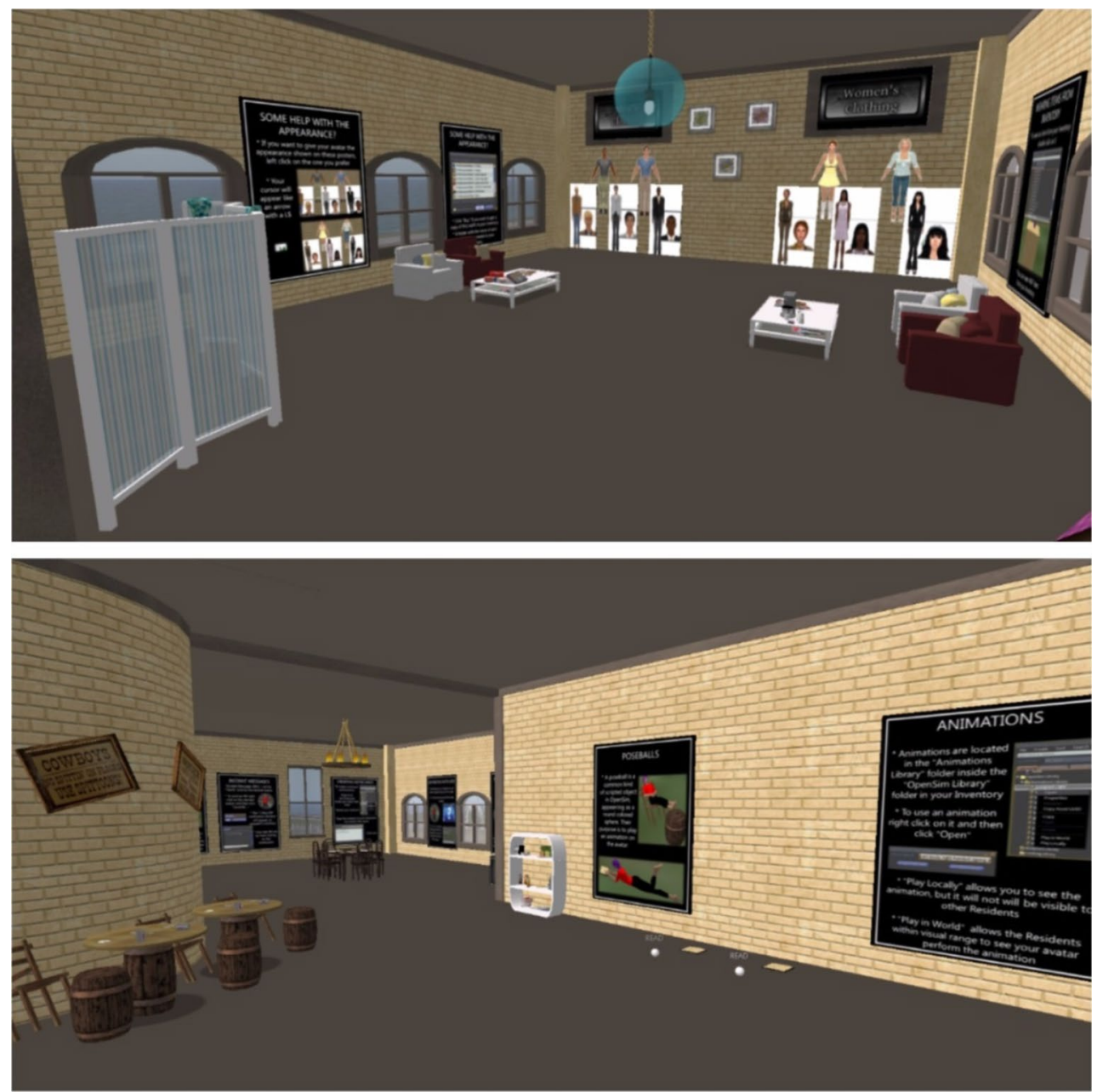

Fig. 2 Rooms inside the orientation building with information about the virtual world and its tools

\section{Results}

One-hundred and ninety-six (196) undergraduate and postgraduate computer science and technology students volunteered to participate in the a priori survey, whilst one-hundred and seventy-eight (178) participated in the a posteriori (Tables 1,2). Nevertheless, since not all the students actively engaged with the virtual world (after filling the a priori survey), a small difference-in the total number of responsescan be seen.

\subsection{Statistical terminology}

Prior to discussing the findings, a brief explanation related to the statistical terminology is given (Agresti 2007).

- Mean $(\overline{\mathrm{x}})$ : The average of the set values. The mean value is also translated in accordance with the Likert scale setup so as to determine the sample's trend.
- Standard deviation $(\sigma)$ : An estimate of the mean variability (spread) of a sample.

- Chi-square's $p$ value: is used to inform the reader if the test results are statistically significant or not $(p>0.05=$ no significance, c.f. Table 10$)$.

\subsection{A priori survey}

Participants' prior experience in the use of virtual worlds was minimal or non-existent (Table 3 ). Those with experience $(n=90)$ described it as generally positive, whilst none of them expressed a very negative opinion (Table 4).

Most participants claimed to have heard at some point some kind of comment related to virtual worlds similar to the one used in our study. The majority classified them as positive and very few reported negative feedback. The trend of the sample was positive with relatively low distribution in participants' responses (Table 5). 

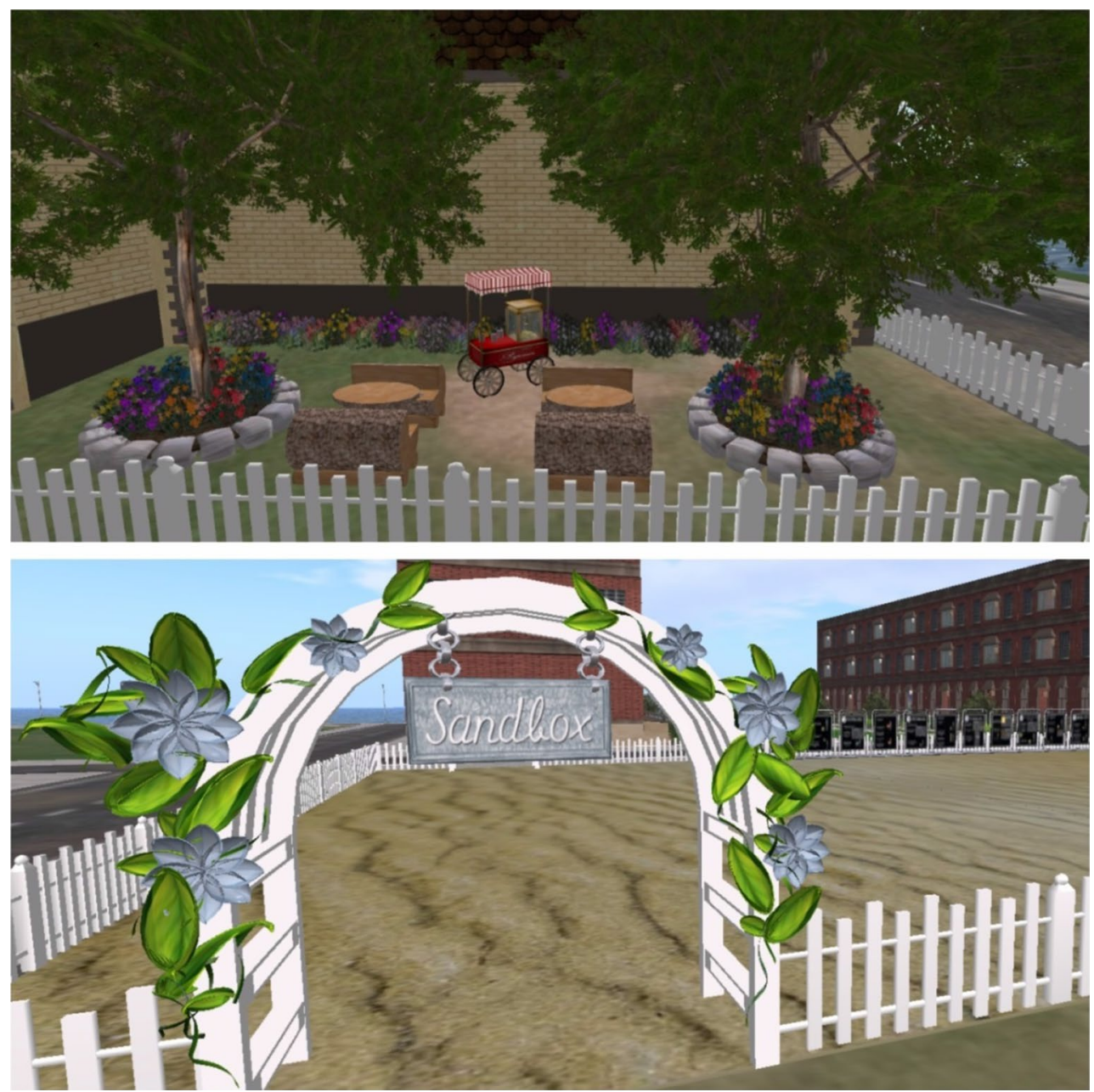

Fig. 3 Leisure-meeting area and the sandbox for experimentation with 3D modelling instructions

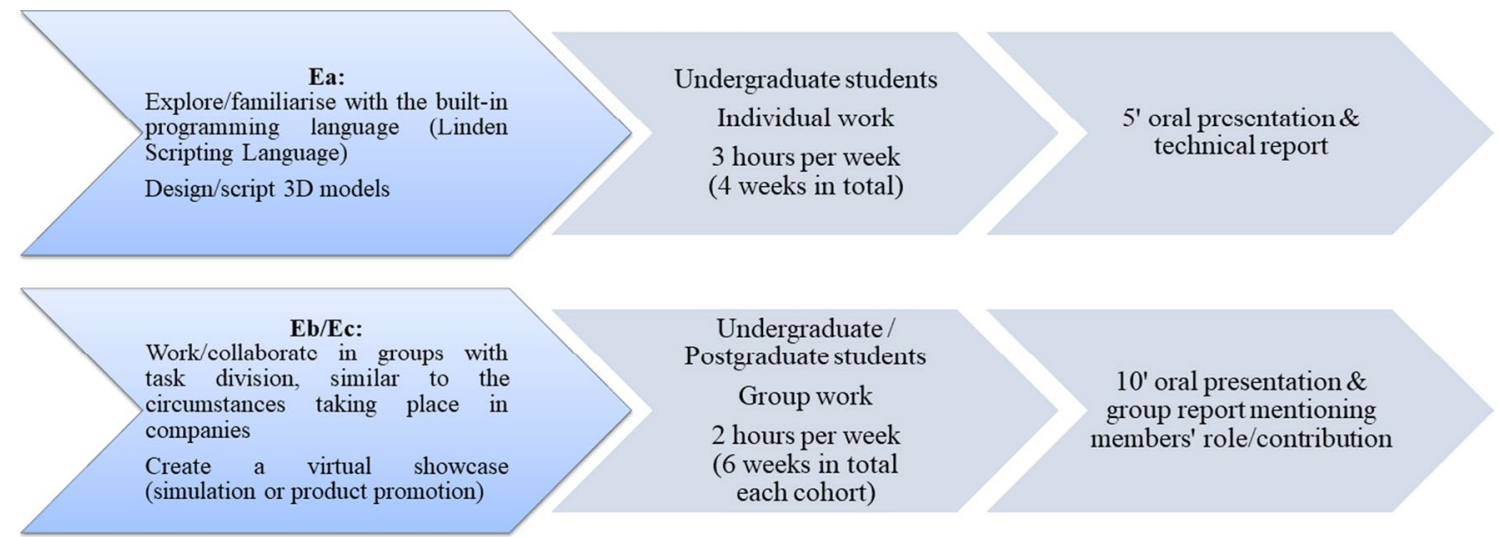

Fig. 4 Students' task during the experiments

Virtual reality products are usually linked with leisure or entertainment and allegedly confused with virtual games. Therefore, questioning our participants' opinion about the value of using a virtual world for educational practices would reveal their personal thoughts and preconceptions about this approach. For most participants, the inclusion of a virtual world in the teaching curriculum would have no considerable impact (positive or negative), 
Table 1 Identity of the sample participated in the a priori survey

\begin{tabular}{|c|c|c|c|c|c|c|c|}
\hline \multicolumn{2}{|c|}{ Gender } & \multicolumn{2}{|l|}{ Academic level } & \multicolumn{4}{|l|}{ Age } \\
\hline Male & Female & Undergraduate & Postgraduate & $18-25$ & $26-35$ & $36-45$ & 46 or older \\
\hline 167 & 29 & 154 & 42 & 108 & 75 & 13 & 0 \\
\hline $85.2 \%$ & $14.8 \%$ & $78.57 \%$ & $21.43 \%$ & $55.1 \%$ & $38.27 \%$ & $6.63 \%$ & $0 \%$ \\
\hline
\end{tabular}

Table 2 Identity of the sample participated in the a posteriori survey

\begin{tabular}{|c|c|c|c|c|c|c|c|}
\hline \multicolumn{2}{|l|}{ Gender } & \multicolumn{2}{|l|}{ Academic level } & \multicolumn{4}{|l|}{ Age } \\
\hline Male & Female & Undergraduate & Postgraduate & $18-25$ & $26-35$ & $36-45$ & 46 or older \\
\hline 152 & 26 & 125 & 53 & 139 & 34 & 3 & 2 \\
\hline $85.39 \%$ & $14.6 \%$ & $70.22 \%$ & $29.77 \%$ & $78.08 \%$ & $19.1 \%$ & $1.68 \%$ & $1.12 \%$ \\
\hline
\end{tabular}

Table 3 Question about prior experience

\begin{tabular}{lcc}
\hline & $(\%)$ \\
\hline 1. My experience in virtual worlds like Second Life/OpenSim is: \\
None & 106 & 54.08 \\
Up to a week & 37 & 18.88 \\
Up to a month & 20 & 10.2 \\
More than a month but $<6$ & 20 & 10.2 \\
More than 6 months but less than a year & 10 & 5.1 \\
More than 1 year & 3 & 1.53 \\
\hline
\end{tabular}

Even though the neutral response in the following statement gathered the highest score, the positive and negative answers collected an almost equal amount, with the negative ones slightly outnumbering the positive. Specifically, the number of participants who would prefer not to use the virtual world in the context of their university studies was equal with those who were happy with this decision. Therefore, the main difference lies between the two extremes where, only a few students claimed that they would opt not to use the virtual world, if they could have this option (Table 7).
Table 4 Describing prior experience

\begin{tabular}{|c|c|c|c|c|c|c|c|}
\hline & & $(\%)$ & & $(\%)$ & $\overline{\mathrm{x}}$ & (mean) & $\sigma$ \\
\hline \multicolumn{8}{|c|}{ 2. I could generally describe my prior experience in such virtual worlds as: } \\
\hline Very positive & 12 & 6.12 & \multirow{5}{*}{$\begin{array}{l}\text { With expe- } \\
\text { rience }\end{array}$} & 13.33 & \multirow[t]{6}{*}{3.65} & \multirow[t]{6}{*}{ Positive } & \multirow[t]{6}{*}{0.76} \\
\hline Positive & 39 & 19.9 & & 43.33 & & & \\
\hline Neither positive nor negative & 35 & 17.86 & & 38.89 & & & \\
\hline Negative & 4 & 2.04 & & 4.44 & & & \\
\hline Very negative & 0 & 0 & & 0 & & & \\
\hline I have no prior experience & 106 & 54.08 & & & & & \\
\hline
\end{tabular}

Table 5 Question about biases and preconceptions

\begin{tabular}{|c|c|c|c|c|c|c|c|}
\hline & & $(\%)$ & & $(\%)$ & $\overline{\mathrm{x}}$ & (mean) & $\sigma$ \\
\hline \multicolumn{8}{|c|}{ 3. The comments I have heard about the use of such virtual worlds were generally: } \\
\hline Very positive & 18 & 9.18 & Have heard comments & 11.76 & 3.60 & Positive & 0.87 \\
\hline Positive & 73 & 37.24 & & 47.71 & & & \\
\hline Neither Positive nor Negative & 50 & 25.51 & & 32.68 & & & \\
\hline Negative & 7 & 3.57 & & 4.58 & & & \\
\hline Very negative & 5 & 2.55 & & 3.27 & & & \\
\hline I have heard no comments & 43 & 21.94 & & & & & \\
\hline
\end{tabular}

as far as the educational outcome is concerned. This is also confirmed from the sample's neutral trend. Lastly, the fact that participants' responses were fairly spread further supports the aforementioned trend (Table 6). 


\subsection{Glance at the observation findings}

Aiming to make the observation process as effective as possible, a checklist was developed and included the following categories (Table 8). Each category consisted of a set of focus points which were utilised to record the frequency of repentance of each action under a $30 \mathrm{~s}$ rotation.

The following is a summary of the findings derived from the observations (Christopoulos et al. 2017). A highlight prior to discussing our findings in detail is that students who went through the orientation process were overall keener to interact both with their fellow students and the world. Furthermore, they had an increased willingness to use the inworld tools more intensively and often as opposed to those who partially or even completely disregarded the existence of the orientation area. In addition, these students found the whole process more enjoyable, constructive and rewarding. Indeed, having the necessary knowledge base to deal with the tools of the world helped students to work on their task without being distracted in search of information on the web or struggling to understand the in-world operations.
On the other hand, those who did not opt to orient themselves properly were observed, almost constantly, struggling to deal with the world's tools and their assignment, by extension. The impact of the orientation process was also visible on the way students' perceived the avatar modification process. Those who followed the available instructions were usually the ones who were having more intense modifications on their avatars' appearance compared to others. As mentioned in the literature, avatar embodiment (Childs 2010) is, indeed, one of the key factors to achieve greater levels of engagement and, therefore, better learning results. Nevertheless, the direct references made to avatars were overall limited. However, given that students were simultaneously co-present in both environments, the use of the chat tool or any other non-verbal in-world communication method was also limited, since this need was being primarily covered in the physical classroom.

Finally, students' willingness to stay in-world and, by extension, the physical classroom for extra time was something that was observed during more than half of the times that the observation practical sessions lasted; hence, this is
Table 6 Question about the use of virtual worlds in education

Table 7 Preference indication regarding the exclusion of the virtual world for learning

\begin{tabular}{lccccc}
\hline & & $(\%)$ & $\overline{\mathrm{x}}$ & (mean) & $\sigma$ \\
\hline 4. I am of the opinion that the & use of & virtual world & in & an educational context has nothing to offer me & \\
Strongly agree & 7 & 3.57 & 2.75 & Neither agree nor disagree & 1.05 \\
Agree & 42 & 21.43 & & & \\
Neither agree nor disagree & 69 & 35.2 & & \\
Disagree & 51 & 26.02 & & \\
Strongly disagree & 27 & 13.78 & & \\
\hline
\end{tabular}

\begin{tabular}{lccclc}
\hline & $(\%)$ & $\overline{\mathrm{x}}$ & (mean) & $\sigma$ \\
\hline $\begin{array}{l}\text { 5. I would prefer it if the use of } \\
\text { in }\end{array}$ & & virtual & world had not been part of the practical sessions I am enrolled \\
Strongly agree & 14 & 7.14 & 2.87 & Neither agree nor disagree & 1.14 \\
Agree & 50 & 25.51 & & & \\
Neither agree nor disagree & 56 & 28.57 & & \\
Disagree & 50 & 25.51 & & \\
Strongly disagree & 26 & 13.27 & & \\
\hline
\end{tabular}

Table 8 Categories of the observation checklist

\begin{tabular}{lll}
\hline Physical classroom & Virtual world & Physical classroom and virtual world \\
\hline $\begin{array}{l}\text { Students' in-class talking and making comments about } \\
\text { the virtual world }\end{array}$ & $\begin{array}{c}\text { Students' in-world talking and making } \\
\text { comments about the virtual world }\end{array}$ & Students' willingness to remain in-world \\
Student attitude towards the use of the virtual world & $\begin{array}{l}\text { Student identity and avatar identity } \\
\text { Interactions with the world }\end{array}$ & \\
Student identity and avatar identity & In-world non-verbal communication & \\
\hline
\end{tabular}


a good indication that confirms their engagement with the world and their project.

\subsection{A posteriori survey}

The vast majority agreed to all the given statements, whilst in all cases the sum of the positive responses was higher than the sum of the negative ones. However, participants chose the neutral response quite frequently and also with greater frequency than the negative ones (Table 9).

As the main body of each statement is repeated, the following abbreviations are used:

- Statement Nr. Student-to-World: Interacting with the content of the virtual world in the context of the practical sessions...(e.g.) is a good reason for me to use a virtual world (Table 10).

- Statement Nr. Student-to-Student: Interacting with other students of the virtual world in the context of the practical sessions... (e.g.) is a good reason for me to use a virtual world (Table 10).

Statements 1 and 12 The main targets in designing the orientation area were: (1) to help students familiarise themselves with the world and its tools and (2) make the virtual environment more attractive for them by providing ideas for development. In order to achieve our goals, we provided students with various information related to the $3 \mathrm{D}$ modelling and coding tools, using a combination of both interactive and non-interactive objects. That way, they were able to quickly

Table 9 Direct comparison of participants' responses

\begin{tabular}{llll}
\hline & Positive responses & Neutral responses & $\begin{array}{l}\text { Negative } \\
\text { responses }\end{array}$ \\
\hline $\begin{array}{l}\text { Student- } \\
\text { to-world } \\
\text { interac- } \\
\text { tions }\end{array}$ & 120.78 & 37.57 & 19.64 \\
$\begin{array}{c}\text { Student-to- } \\
\text { student } \\
\text { interac- } \\
\text { tions }\end{array}$ & 120.43 & & \\
\hline
\end{tabular}

glance at the learning material and make some practice in real time. Statements 1 and 12 examined the impact that this process had on their willingness to use the virtual world.

Most of the participants agreed in both statements that the network of interactions developed in-world was a good reason for them to use it. However, the higher standard deviation value in statement 12 gives the indication that the interactions that participants had with their fellow students contributed slightly less to their willingness to engage with the world. Even though statistically there is no significant difference, the lower mean value that statement 12 has also gives an indication that student-to-student interactions were less intense compared to those occurring between the students and the world (Table 10).

Statements 2 and 13 One of the main reasons for using the virtual world in our teaching agenda was to increase learner engagement as this could aid our teaching and help our students achieve better learning results. Thus, by using the orientation area to help them familiarise with the world, we expected to have increased levels of in-world presence and, therefore, engagement. Statements 2 and 13 asked for the students' opinion regarding the impact that the orientation process had on their in-world presence.

The interactions occurring between the students and the world were more intense, compared to those occurring among the students themselves, though with slightly less impact. Both statements have quite low standard deviation values which, along with their means, reveal a positive trend towards both statements (Table 11).

Statements 3 and 14 Constructivist learning theory (Vygotsky 1978), on which our research relies, indicates that students have better learning results when experiencing the knowledge or the learning material. As already mentioned, the way that the orientation area was developed was aiming not only to provide students with the theoretical knowledge or the necessary information that could help them cope with the needs of their assignment, but also to allow them experiment or practice in real time before getting hands-on experience on their actual work. That said, it was deemed necessary to ask students whether this process helped them
Table 10 Results of statements 1 and 12

\begin{tabular}{|c|c|c|c|c|c|c|c|c|}
\hline & Strongly agree & Agree & $\begin{array}{l}\text { Neither } \\
\text { agree nor } \\
\text { disagree }\end{array}$ & Disagree & $\begin{array}{l}\text { Strongly } \\
\text { disagree }\end{array}$ & $\overline{\mathrm{x}}$ & $\sigma$ & $p$ \\
\hline \multicolumn{9}{|c|}{...is a good reason for me to use a virtual world } \\
\hline 1 Student-to-world & 32 & 94 & 35 & 10 & 7 & 3.75 & 0.94 & 0.233951 \\
\hline 12 Student-to-student & 19 & 93 & 40 & 16 & 10 & 3.53 & 0.99 & \\
\hline
\end{tabular}


experience the knowledge both whilst practicing in the orientation area and during their actual work.

The vast majority agreed that both types of interactions contributed positively to experience the learning material. Nevertheless, the interactions occurred between the students and the world had slightly greater impact to achieving this outcome. Indeed, this was the main reason for using this technology as part of this class, i.e. the knowledge acquisition through interactions. However, the various learning approaches that are used to engage students with the learning material and allow them to experience the knowledge to the maximum extent cannot fit with the personality and preferences of all learners. As a result, several participants maintained a neutral position towards this statement, whilst very few disagreed (Table 12).

Statements 4 and 15 Aiming to enhance the already ludic nature of the world, as discussed in Sect. 5, a large variety of content was utilised to turn the orientation area into a small 'playground'. A few examples are the sandbox area, which provided students with instructions related to $3 \mathrm{D}$ content development and programming whilst allowing them to perform such actions in real time. Moreover, the 'beauty salon' provided students with instructions and information related to avatars' appearance editing, whereas for those who were not interested to engage with this process, various pre-made outfits were freely available to them. The meeting room offered students the opportunity to hold group meetings and exchange ideas or discuss their progression in an office-like environment, whilst the 'countryside' resting area (outside the orientation building) aimed at offering students the opportunity to have small breaks to relax and detach themselves from work. In order to make the learning process and material more interesting and attractive for them, the design of the aforementioned areas was based on the edutainment theory (Deterding et al. 2011).

The network of interactions that was developed in-world made the learning material more attractive for most students. However, several were those who did not perceive it the same way as they claimed that it had no actual impact on that. In fact, examining the negative responses, it seems that the learning material became even unappealing for a considerable number of participants. This can be attributed mainly to students' personal choices and learning styles. The trend of the sample, in both statements, is positive, without having significant difference. Yet, the quite high standard deviation values provide a clear indication of how spread students' thoughts are (Table 13).
Table 11 Results of statements 2 and 13

Table 12 Results of statements 3 and 14

Table 13 Results of statements 4 and 15

\begin{tabular}{|c|c|c|c|c|c|c|c|c|c|}
\hline & & Strongly agree & Agree & $\begin{array}{l}\text { Neither } \\
\text { agree nor } \\
\text { disagree }\end{array}$ & Disagree & $\begin{array}{l}\text { Strongly } \\
\text { disagree }\end{array}$ & $\overline{\mathrm{x}}$ & $\sigma$ & $p$ \\
\hline \multicolumn{10}{|c|}{...made me feel I am actually present in the virtual world } \\
\hline 2 & Student-to-world & 24 & 86 & 45 & 19 & 4 & 3.60 & 0.92 & 0.510663 \\
\hline 13 & Student-to-student & 20 & 89 & 43 & 16 & 10 & 3.52 & 0.99 & \\
\hline
\end{tabular}

\begin{tabular}{|c|c|c|c|c|c|c|c|c|}
\hline & Strongly agree & Agree & $\begin{array}{l}\text { Neither } \\
\text { agree nor } \\
\text { disagree }\end{array}$ & Disagree & $\begin{array}{l}\text { Strongly } \\
\text { disagree }\end{array}$ & $\overline{\mathrm{x}}$ & $\sigma$ & $p$ \\
\hline \multicolumn{9}{|c|}{...made me 'experience the knowledge' } \\
\hline 3 Student-to-world & 33 & 92 & 40 & 7 & 6 & 3.78 & 0.90 & 0.425483 \\
\hline 14 Student-to-student & 23 & 91 & 44 & 13 & 7 & 3.61 & 0.93 & \\
\hline
\end{tabular}

\begin{tabular}{|c|c|c|c|c|c|c|c|c|}
\hline & Strongly agree & Agree & $\begin{array}{l}\text { Neither } \\
\text { agree nor } \\
\text { disagree }\end{array}$ & Disagree & $\begin{array}{l}\text { Strongly } \\
\text { disagree }\end{array}$ & $\overline{\mathrm{x}}$ & $\sigma$ & $p$ \\
\hline \multicolumn{9}{|c|}{...made the learning material more attractive for me } \\
\hline 4 Student-to-world & 37 & 79 & 37 & 18 & 7 & 3.67 & 1.03 & 0.524717 \\
\hline 15 Student-to-student & 29 & 90 & 34 & 14 & 11 & 3.62 & 1.04 & \\
\hline
\end{tabular}


Statements 5 and 16 Students' participation in and engagement with the classes/practical sessions are generally considered to be affected by the nature, the content and the attractiveness of the teaching subject. From our perspective, as instructional designers, we designed the orientation area in a way capable of touching upon all the aforementioned parameters. Nevertheless, whether students' willingness to participate more gladly in the practical sessions had been affected by these actions was something that had to be questioned.

Even though both types of interactions affected equally students' willingness to participate in the practical sessions, the opportunity given to them to work in groups and, therefore, interact with each other contributed slightly more to achieving that goal. Nevertheless, a considerable portion of students reported that interactions had no or, in some cases, even negative impact on that. Even though participants' responses are quite spread, the overall trend of the sample remains fairly positive (Table 14 ).

Statements 6 and 17 As mentioned in the previous statements (statements 4 and 15), the playful nature of these environments allows educators to utilise a different teaching and learning approach, compared to traditional learning methods, enabling them to achieve better learning results and higher levels of engagement. In fact, the core element of edutainment is the 'fun' students get whilst learning. The orientation process was expected to play a crucial role in that, as it was meant to 'equip' students with all the necessary knowledge to make the most out of it. Nevertheless, the fact that something is different, or, in this case, 'playful' does not necessarily mean that it will be fun too, and this is what statements 6 and 17 examined.
Participants reported that they, indeed, had fun whilst learning. Both types of interactions contributed almost equally to achieving it, even though the interactions occurring between the students and the world had slightly greater impact on that. Considering the very positive trend of the sample and the low values of the standard deviations, it can be claimed that students truly enjoyed their time (Table 15).

Statements 7 and 18 Getting students to attend a practical session, considering the strict university policies (e.g. attendance recording), may not always be that challenging. However, managing to make them attractive enough for students definitely is. By all means, the use of such environment in a blended teaching/learning approach, the reshaping of the process of delivering the learning material and the existence of the orientation area were all expected to make the practical session more attractive for students. The extent to which this goal has been achieved is examined through the following statements.

The vast majority agreed that breaking their routine by doing something different or, at least 'uncommon', made the practical sessions more attractive for them. Though, slightly, the interactions that students had with their classmates seem to have contributed more to achieving that outcome. Nevertheless, there is no learning method that can be completely appropriate or suitable for all learners. That said, for a small, yet, considerable portion of students, the use of a virtual world and the interactions they could have within it was not the medium that would make their practical session attractive. Nevertheless, the sample's positive trend is clearly demonstrated in both statements without having significant statistical differences (Table 16).
Table 14 Results of statements 5 and 16

Table 15 Results of statements 6 and 17

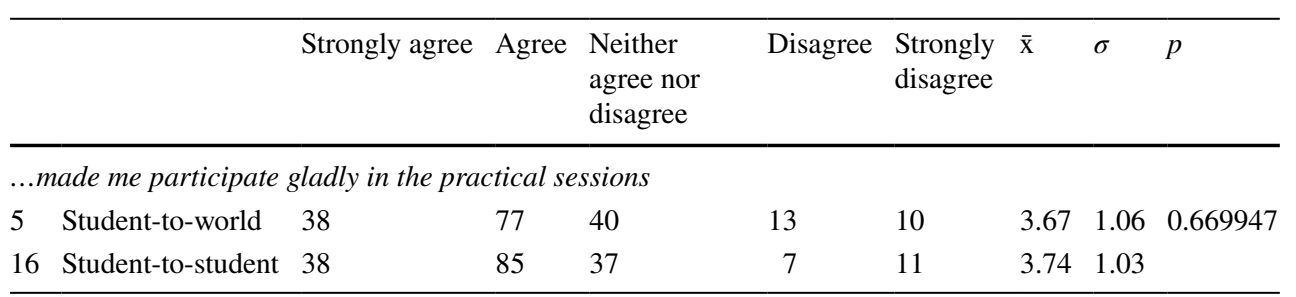

\begin{tabular}{|c|c|c|c|c|c|c|c|c|}
\hline & Strongly agree & Agree & $\begin{array}{l}\text { Neither } \\
\text { agree nor } \\
\text { disagree }\end{array}$ & Disagree & $\begin{array}{l}\text { Strongly } \\
\text { disagree }\end{array}$ & $\overline{\mathrm{x}}$ & $\sigma$ & $p$ \\
\hline \multicolumn{9}{|l|}{...was fun } \\
\hline 6 Student-to-world & 60 & 85 & 24 & 5 & 4 & 4.07 & 0.88 & 0.124046 \\
\hline 17 Student-to-student & 42 & 97 & 21 & 9 & 9 & 3.86 & 0.99 & \\
\hline
\end{tabular}


Statements 8 and 19 Considering that each learner has a different way of acquiring and constructing knowledge, the ease of learning is, by default, a subjective topic to discuss. Nevertheless, the way interactions can affect learner engagement is one of the main goals that this study aims to investigate. Thus, the orientation area aimed at engaging most of - if not all - the students with the educational activities and the learning material, aiming to make the learning process easier for them compared to 'just studying'. Whether or not this has been achieved is examined in the following statements.

The 3D element, the vividness and the playful nature of the virtual world made the learning process easier, as opposed to just studying, for most participants. Even though both types of interactions contributed towards that, the ones with the content of the world had slightly greater impact on it (Table 17).

Statement 9 As seen during our first experiment (Christopoulos et al. 2014), the importance of having pre-existing content for exploration and sightseeing was deemed to be a key element in learner engagement. Nevertheless, considering that during this experiment, for at least a couple of weeks, there was no significant content developed by former students (for exemplification purposes) or the students themselves; the orientation area had to cover that need and offer students a place to explore. Given that this was an exclusively student-to-world interaction, only this side could be examined.

The 3D modelling and scripting are the main sources of interactions that users may have with the content of such worlds. For most of the participants, the content exploration-originating either from other students or the instructional designer-was considered a pleasant process. Nevertheless, at the other extreme, students reported that the exploration of the world's content was a rather irrelevant process for them, whilst for an almost equal number of participants this process was not included in their agenda (Table 18).

Statement 10 This statement was eventually developed after pondering on the definition of the orientation process. A well-oriented student, capable of using all the in-world tools, would (theoretically) have more chances to design and develop more sophisticated objects and scripts compared to others, thus making the entire process more enjoyable and pleasant. Likewise, using (interacting with) the objects that students have created themselves can be considered as a good indication of being engaged with the world. Nevertheless, as it is questionable whether this engagement is the outcome of actual pleasure or simply part of 'doing the task', it was deemed appropriate to ask students directly.

Table 16 Results of statements 7 and 18

\begin{tabular}{|c|c|c|c|c|c|c|c|c|c|}
\hline & & Strongly agree & Agree & $\begin{array}{l}\text { Neither agree } \\
\text { nor disagree }\end{array}$ & Disagree & $\begin{array}{l}\text { Strongly } \\
\text { disagree }\end{array}$ & $\overline{\mathrm{x}}$ & $\sigma$ & $p$ \\
\hline \multicolumn{10}{|c|}{...made the practical session more attractive for me } \\
\hline 7 & Student-to-world & 42 & 83 & 33 & 11 & 9 & 3.77 & 1.03 & \multirow[t]{2}{*}{0.860036} \\
\hline 18 & Student-to-student & 40 & 89 & 26 & 13 & 10 & 3.86 & 0.99 & \\
\hline
\end{tabular}

Table 17 Results of statements 8 and 19

\begin{tabular}{|c|c|c|c|c|c|c|c|c|c|}
\hline & & Strongly agree & Agree & $\begin{array}{l}\text { Neither } \\
\text { agree nor } \\
\text { disagree }\end{array}$ & Disagree & $\begin{array}{l}\text { Strongly } \\
\text { disagree }\end{array}$ & $\overline{\mathrm{x}}$ & $\sigma$ & $p$ \\
\hline \multicolumn{10}{|c|}{...made learning easier for me compared to just studying } \\
\hline 8 & Student-to-world & 43 & 78 & 30 & 17 & 10 & 3.71 & 1.10 & 0.170211 \\
\hline 19 & Student-to-student & 35 & 83 & 35 & 8 & 17 & 3.62 & 1.13 & \\
\hline
\end{tabular}

Table 18 Results of statement 9

\begin{tabular}{llllllll}
\hline & Strongly agree & Agree & Neither agree nor disagree & Disagree & Strongly disagree & $\overline{\mathrm{x}}$ & $\sigma$ \\
\hline ...pleased me a lot, especially & when I was exploring and sightseeing \\
9 & Student-to-world & 37 & 77 & 38 & 14 & 12 & 3.63 \\
\hline
\end{tabular}


Students claimed that the time spent to design, script and use their own objects was definitely a pleasant process. Making a direct comparison of the responses given to this statement with statement 11 , it can be seen that using their own objects was more enjoyable, compared to those developed by others (Table 19).

Statement 11 This statement was developed in conjunction with statement 10. Exploration, sightseeing and use of objects developed by others, including the content developed by the instructional designers, are all different types of interactions that students can have with the world's content. As all the above are grouped under the passive learning approach and referring back to our main hypothesis that interactions bridge engagement and learning, it was considered worthwhile to ask students whether using virtual objects developed by others was a pleasant process for them or not.

Most of the participants would opt to explore the content of the world for various reasons. However, the use of objects developed by others was probably not one of them. Thus, even though for a fairly high number of participants this process was interesting and pleasant, for an almost equally high number of students it made no difference or even displeased them (Table 20).

Statement 20 The inclusion of a virtual world in the teaching agenda was expected to offer students the opportunity to have fun whilst engaging with the educational material. Once again, the orientation area was meant to play a crucial role in that, as students were expected not only to familiarise themselves with the world and its tools, but also to get various stimuli for development and experimentation. However, learning is linked with mistakes and we wanted to know the way our students would perceive their mistakes, as this could be one more indication of additional engagement.

The vast majority agreed that observing the unexpected results of their own mistakes pleased them a lot, as it was another opportunity to laugh and entertain themselves. Indeed, as it is commonly known, 'we learn from our mistakes' and, therefore, the responses to this statement provide a strong indication that students did spend time to experiment and learn (Table 21).

- Open-ended question: In your opinion, what would have helped you become more engaged with the virtual world?

The last part of this questionnaire offered participants the option to propose ways that would have made them become more engaged with the virtual world. This question was open ended and therefore optional. Out of the 178 participants, 58 provided an answer (32.5\%). Based on the grounded theory (Strauss and Corbin 1998), these answers can be classified in the following categories.

\section{a. Time limitations}

Participants (12) claimed that the duration of their project was not sufficient enough to allow them to understand the philosophy of the virtual world, familiarise with its tools and programming language, acquire the necessary skills and produce the desired outcome.

Table 19 Results of statement 10

\begin{tabular}{|c|c|c|c|c|c|c|c|c|}
\hline & & Strongly agree & Agree & Neither agree nor disagree & Disagree & Strongly disagree & $\overline{\mathrm{x}}$ & $\sigma$ \\
\hline \multicolumn{9}{|c|}{...pleased me a lot, especially when I was using the virtual objects I created } \\
\hline 10 & Student-to-world & 40 & 92 & 33 & 9 & 4 & 3.87 & 0.89 \\
\hline
\end{tabular}

Table 20 Results of statement 11

\begin{tabular}{|c|c|c|c|c|c|c|c|c|}
\hline & & Strongly agree & Agree & Neither agree nor disagree & Disagree & Strongly disagree & $\overline{\mathrm{x}}$ & $\sigma$ \\
\hline \multicolumn{9}{|c|}{...pleased me a lot, especially when I was using others' virtual objects } \\
\hline 11 & Student-to-world & 23 & 74 & 52 & 20 & 9 & 3.46 & 1.02 \\
\hline
\end{tabular}

Table 21 Results of statement 20

\begin{tabular}{llllllll}
\hline \multicolumn{1}{c}{ Strongly agree } & Agree & Neither agree nor disagree & Disagree & Strongly disagree & $\overline{\mathrm{x}}$ & $\sigma$ \\
\hline ..pleased me & a lot, especially & when we were laughing with & our mistakes \\
20 & Student-to-student & 38 & 86 & 40 & 8 & 6 & \\
\hline
\end{tabular}




\section{b. Lack of pre-existing content}

Even though the freely available online content of example scripts and libraries related to the in-world programming language is fairly massive, participants (16) wished to have more example content available in-world. Even though several scripted objects were present in the orientation area, their main aim was to provide students with the basic information about the world and its tools though they could also act as examples of how to design and turn objects into interactive creations. Nevertheless, participants seemed to be looking for examples of the artefacts they were asked to create as part of their assignment. Furthermore, one student mentioned that having mini virtual games could have increased the levels of engagement because of his interest to discover more about the way they are coded.

\section{c. Technical issues}

All the technical issues that students faced whilst using the virtual world can be grouped in three sub-categories.

- The first sub-category includes the answers given by a portion of students (7) concerning the quality of graphics. Specifically, for these students the engagement with the world would have probably been increased if the frame rate speed, the resolution, and the graphical user interface were better. Furthermore, one student felt that the option of editing objects, whilst observing them in the first person, would have worked positively on his engagement. Lastly, another participant reported the lack of having a large variety of 3D models compatible with the virtual world.

- Regarding the second sub-category, students (8) stated that the experiential nature of the scripting language and the various bugs that occasionally occurred decreased their engagement; therefore, they suggested that its functions and operations should be improved.

- The last sub-category includes general issues such as more options to customise avatars or the voice input. Indeed, such environments offer the option to edit avatar's appearance in diverse ways. Nevertheless, it should be mentioned that this process is fairly timeconsuming and demanding, in order to achieve a desirable outcome. Finally, one student mentioned the lack of primitives within the system. This response can be examined from two perspectives: (1) the in-world primitives' gallery (polygons) that users modify to design their artefacts or (2) the maximum allowed primitives that students could use to produce their showcase due to the restrictions that were applied in the assignment description.

\section{d. Assignment}

Interestingly, a few students (5) made a special reference to their assignment. Indeed, the nature of the assignment weighs equally with the design of the in-world activities that instructional designers plan for their students, as each one of them complements the other. Even though the design of the in-world activities is part of this study, the assignment brief or set-up is, however, out of the scope of this discussion. Nevertheless, the fairly similar responses given by two students are worth to be briefly discussed, as they suggested that higher levels of engagement would have been achieved if the use of the virtual had not been part of this particular assignment but, instead, if there was an assignment exclusively focused on the virtual world without including other tasks (e.g. physical artefact development, documentation about project management methodology).

\section{e. Instructions}

This category refers to the instructions offered to students. In particular, a relatively small but considerable portion of students (4) would like to have more information about this technology or its impact on their learning outcome. In addition, what should also be mentioned is the lack of clear guidance in regard to the aim and scope of their project.

\section{f. Student personality}

The last category includes students' (3) opinions that could not be included in any of the other categories. Specifically, one student mentioned that his engagement was decreased due to the lack of having other students working with him, whilst another claimed that the nature of his discipline is unrelated to the use of such technology. The third student claimed that a platform more tailored and oriented to cover 3D modelling and programming purposes (e.g. Unity 3D) would have had better impact on his engagement.

\section{Summary}

As already discussed in the literature (Childs 2010; de Freitas et al. 2010; Herbet et al. 2012; Hockey et al. 2010; Johnson et al. 2009), many researchers focus exclusively on the interactions that take place within the virtual world, where the environment provides the primary medium for communication and interaction. Nevertheless, the main 
contribution of our study is that it examines interactions in conjunction with their impact to learner engagement, in the context of using an orientation process to enhance learners' familiarity with the virtual world and boost the incentives for more intense interactions and therefore higher levels of engagement.

\subsection{A priori survey}

The sample consisted of both undergraduate and postgraduate university students with relatively minimal or nonexistent prior experience regarding the use of such environments. Participants with prior experience-for a short or long period of time-reported that it was overall positive, though a considerable number of them maintained a neutral position, whilst only a few a negative one. In any case, for more than half of the sample this would be the first time that they would make use of such platform.

The vast majority had heard positive comments, as far as this type of virtual world is concerned. Nevertheless, a significant portion claimed that they had come across neutral ones, whilst very few reported that they had got negative feedback. As most of them claimed that they considered it to be a worthwhile project, it can be assumed that this had some sort of effect on their opinion or preconceptions. Finally, by cross-examining participants' opinion between the last two statements, a clear trend of how the sample is divided can be seen, as almost equal was the number of those who claimed that they would not prefer the virtual world as part of their practical sessions with that of those who claimed the opposite.

\subsection{A posteriori survey}

According to participants, both types of interactions affected almost equally the levels of their engagement with the virtual world. Nevertheless, learners considered the interactions occurring between them and the world's content as slightly more important compared to those occurring among them and other students. This can be attributed to several factors varying from the existence of the orientation area to the content developed by the students themselves or even others. At the same time, the fact that students had the opportunity to interact with others in the physical classroom should not be disregarded, but, instead, it should be considered as a fact of major importance and benefit to the students.

A. Interactions both with the content of the virtual world and among students.

The vividness of the world's graphics and the freedom given to students to virtually reconstruct and observe their imaginary creations 'alive' made the learning material more attractive for them and helped them experience the knowledge. In addition to this, the ludic aspect of the virtual world and the interactions occurring with other students also increased the participants' willingness to engage with the learning material and made the learning process easier for them. The fact that participants were simultaneously copresent in the physical classroom affected rather negatively the sense of in-world presence, as they were interacting quite often with each other (physically).

\section{B. Interactions with the content of the virtual world.}

The impact that student-to-world interactions have on student feelings towards the virtual world is slightly more positive than that of student-to-student. Indeed, participants agreed that the alternative way of working and learning in the virtual world and the opportunities given to them to experiment with the in-world programming language was the most attractive type of interaction which strongly affected their engagement. Likewise, the design and creation of 3D models had an equally important role to this outcome. Even though most of the participants claimed that the use of the objects and scripts created by themselves was a pleasant and enjoyable process altogether, the use of objects developed by other students had, without a doubt, considerably less impact. This subsequently affected their willingness to explore the existing content in the virtual world created either by other students or the instructional designer.

\section{Interactions with other students.}

The utilisation of a virtual world for learning practices was a medium mostly unexplored and unknown for most participants. Thus, during the exploration process, unexpected results were occurring and that made-most of them-laugh with their mistakes. Likewise, the opportunity to have small breaks and perform actions irrelevant to their project was something that was also acknowledged and highlighted as important. An interesting observation can be drawn after cross-examining the responses given in the statements regarding learning from and teaching others. Specifically, as to the latter, even though participants claimed that they had the opportunity to teach others things they already knew, this was not equally reflected or acknowledged by the responses given in the statement concerning the opportunities given to learn what other students already knew. This can be attributed to the fact that students' interactions in the virtual world were quite infrequent, as opposed to the ones in the physical classroom. 


\section{Limitations of the study}

The limitations of our study and the factors that have potentially influenced the results-even though were intended to be kept to a minimum-should be duly noted before reaching our conclusion. Due to the set-up of the experiment, all participants were students from the same institution where the researchers work as educators. However, we feel that this population is sufficiently generic to allow certain generalisations to other institutions.

\section{Answer to our question}

Cross-examining both the information gathered during the relevant literature review and the findings from the surveys and observations, it can be concluded that the use of virtual worlds - as a teaching tool or medium - in general, and the induction/orientation process, in particular, can definitely positively affect learner engagement through the network of interactions that can be developed in and between the two environments and the students. In addition, the main hypothesis, i.e. the fact that interactions can aid the learning process by increasing learner engagement, is also confirmed even though more experiments have to be conducted using different set-ups and student cohorts.

Educators who are planning to use virtual environments in their teaching agenda should be prepared and well aware that a considerable amount of time has to be devoted in order to develop interactive and engaging learning activities for their students; in fact, this should be their main goal and priority. Indeed, the literature also points to this direction; as suggested by Zhao et al. (2010), educators who use or plan to use virtual worlds should be ready to acquire a new role, the one of the supporter and instructor.

The various types of actions and interactions that students can have both with the content of the virtual world and with others-such as object creation and manipulation, terrain editing, navigation and communication (Allison et al. 2012; Bredl et al. 2012; Dalgarno and Lee 2010; Herbet et al. 2012; Hockey et al. 2010)—can work as the 'lever' which will help students to engage more with the world and construct their knowledge (Vygotsky 1978). This is eventually the key to success. Finding the way to cover the learning needs and preferences of as many students as possible through different types of stimuli and interactions can significantly increase the chances of having better learning outcomes (Christopoulos 2013).

In this experiment, we examined the impact that the induction process had on learner engagement and it was proven to be of vital importance. Indeed, as with every teaching method or approach, there is no guarantee that all the students will engage with the learning material or enjoy the process, as their personal choices and preconceptions can be opposed to the instructional designer's plans. However, this is where the educator's role should be adapted, or in other words, this is where educators should 'teach' their students how to make the most of the content that has been developed for them, and also encourage them to use it, as it will be for their own benefit.

\section{Conclusions and future work recommendations}

Concluding this paper in one sentence, it can be said that interactions can play a crucial role in learner engagement, if designed appropriately. Specifically, a smooth induction to the tools, the methods, the procedures and the affordances of a virtual world can lead students into having meaningful and engaging interactions. On top of that, students' simultaneous physical and virtual colocation can result in the elimination of the weaknesses of each environment (physical and virtual) and, at the same time, enhance their strengths. Moreover, students that go through a proper orientation process develop the skills needed in order to exploit to the maximum the affordances of a virtual world. Thus, students should be given enough time to orient themselves, familiarise with the world's tools and explore its potentials. It is, also, of vital importance that educators provide students with clear instructions and information regarding the existence and the purpose of the in-world educational content as well as encourage their learners to use it. As far as the role of the instructional designers is concerned, special attention should be paid when designing the orientation process in order to cover-at least - the basic aspects (tools) of the world, but also motivate learners to further explore them by themselves. Indeed, not all the students will be attracted by the same design approach, even though the higher the levels of interactivity with the orientation area are, the higher are the chances to attract learners' attention and for them to engage with the process. Furthermore, learner choices might be opposed to the instructional design, and thus clear instructions and information should be given; in fact, educators should encourage their students to use the in-world infrastructure as the existence of this content has been designed and developed on students' favour. Finally, further identification of the factors that make an orientation area successful as well as the impact of interactions using different set-ups is highly recommended to be examined. The following experiments are suggested as future 
work recommendation as they will also be authors' future work: (1) examination of the impact that the virtual educational and leisure games have on students' interactions and engagement and (2) use of pedagogical artificial intelligence agents to facilitate, disrupt and mislead students' tasks, questioning once again the aforementioned aspects.

\section{Compliance with ethical standards}

Conflict of interest The authors declare that there is no conflict of interests.

Ethical considerations The ethical issues that interfere in this study have been examined by the Research Ethics Committee of the University of Bedfordshire, and researchers have received the required approval to conduct this study.

Open Access This article is distributed under the terms of the Creative Commons Attribution 4.0 International License (http://creativecomm ons.org/licenses/by/4.0/), which permits unrestricted use, distribution, and reproduction in any medium, provided you give appropriate credit to the original author(s) and the source, provide a link to the Creative Commons license, and indicate if changes were made.

\section{References}

Agresti A (2007) An introduction to categorical data analysis, 2nd edn. Wiley-Interscience, Hoboken

Akkoyunlu B, Y1lmaz-Soylu M (2008) Development of a scale on learners' views on blended learning and its implementation process. Internet Higher Educ 11:26-32

Allison C, Campbell A, Davies CJ, Dow L, Kennedy S, McCaffery JP, Miller AHD, Oliver IA, Perera GIUS (2012) Growing the use of virtual worlds in education: an OpenSim perspective. In: Gardner M, Garnier F, Kloos CD (eds) Proceedings of the 2nd European immersive initiative summit. Paris, France, pp 1-13

Anasol PR, Callaghan V, Gardner M, Alhaddad MJ (2012) End-user programming and deconstrutionalism for co-creative laboratory activities in a collaborative mixed-reality environment. In: Gardner M, Garnier F, Kloos CD (eds) Proceedings of the 2nd European immersive education summit (EiED 2012), Departamento de Ingeniería Telemática, Universidad Carlos III de Madrid, Madrid, Spain, pp 171-182

Bainbridge WS (2007) The scientific research potential of virtual worlds. Science 317:472-476

Bartle R (2003) Designing Virtual Worlds. Indianapolis, IN: New Riders

Begg M, Dewhurst D, Macleod H (2005) Game-informed learning: applying computer game processes to higher education. Innovate: J Online Educ 1:6

Bower M, Cram A, Groom D (2010) Blended reality: issues and potentials in combining virtual worlds and face-to-face classes. In: Proceedings of the Australasian Society for Computers in Learning in Tertiary Education (Ascilite). Sydney, pp 129-140

Bredl K, Groß A, Hünniger J, Fleischer J (2012) The avatar as a knowledge worker? How immersive 3D virtual environments may foster knowledge acquisition. Electronic Journal of Knowledge Management 10(1):15-25

Camilleri V, de Freitas S, Montebello M, McDonagh-Smith P (2013) A case study inside virtual worlds: use of analytics for immersive spaces. In: Proceedings of the 3rd international conference on learning analytics and knowledge, (LAK). ACM, New York, USA, pp 230-234

Carter B (2012) Virtual Harlem: an innovative past, an evolving present and an exciting future. In: Gardner M, Garnier F, Kloos CD (eds) Proceedings of the 2nd European immersive initiative summit. Paris, France, pp 24-37

Chafer J, Childs M (2008) The impact of the characteristics of a virtual environment on performance: concepts, constraints and complications. Proc researching learning in virtual environments. Open University, Milton Keynes, UK, pp 94-105

Childs M (2010) Learners' experience of presence in virtual worlds $(\mathrm{PhD})$. University of Warwick, Coventry

Christopoulos A (2013) Higher education in virtual worlds: the use of second life and OpenSim for educational practices (master thesis). University of Bedfordshire, Luton

Christopoulos A, Conrad M, Kanamgotov A (2017) Interaction in situated learning does not imply immersion: virtual worlds help to engage learners without immersing them. In: Proceedings of the 9th International conference on computer supported education. Porto, Portugal, pp 323-330

Christopoulos A, Conrad M, Shukla M (2014) Objects, worlds, and students: virtual interaction in education. J Educ Res Int 2014(2014). https://doi.org/10.1155/2014/318317

Christopoulos A, Conrad M, Shukla M (2017) How do students 'really' interact with virtual worlds? The influence of proper induction for virtual interactions. In: Proceedings of the 8th international conference on computer supported education, SCITEPRESS, Rome, Italy, pp 43-54

Cohen L, Manion L, Morrison K (2011) Research methods in education, 7th edn. Routledge, London

Dalgarno B, Lee MJW (2010) What are the learning affordances of 3-D virtual environments? Br J Educ Technol 41:10-32

Deterding S, Dixon D, Khaled R, Nacke L (2011) From game design elements to gamefulness: defining gamification. In: Proceedings of the 15th international academic MindTrek conference: envisioning future media environments, ACM, New York, pp 9-15

de Freitas S, Rebolledo-Mendez G, Liarokapis F, Magoulas G, Poulovassilis A (2010) Learning asimmersive experiences: Using the four-dimensional framework for designing and evaluating immersivelearning experiences in a virtual world. Br J Educ Technol 41(1):69-85

Dickey MD (2005) Brave new (interactive) worlds: a review of the design affordances and constraints of two 3D virtual worlds as interactive learning environments. Interact Learn Environ 13(1-2):121-137

Elliott JB, Gardner M, Alrashidi M (2012) Towards a framework for the design of mixed reality immersive education spaces. In: Gardner M, Garnier F, Kloos CD (eds) Proceedings of the 2nd European immersive initiative summit, Paris, France, pp 63-76

Freitas S, Rebolledo-Mendez G, Liarokapis F, Magoulas G, Poulovassilis A (2009) Developing an evaluation methodology for immersive learning experiences in a virtual world. In: International conference on games and virtual worlds for serious applications (VS-Games). IEEE, Coventry, UK, pp 43-50

Herbet A, Thompson F, Garnier F (2012) Immaterial art stock: preserve, document and disseminate the pioneering works of art created inside online immersive platforms. In: Gardner M, Garnier F, Kloos CD (eds), Proceedings of the 2nd European immersive education summit, Paris, France, pp 101-113

Hockey A, Esmail F, Jimenez-Bescos C, Freer P (2010) Built environment education in the era of virtual learning. In: W089special track 18th CIB World Building Congress, Salford, pp 200-217

Hoshi K, Pesola UM, Waterworth EL, Waterworth J (2009) Tools, perspectives and avatars in blended reality space. Stud Health Technol Inf 144:91-95 
Johnson CM, Vorderstrasse AA, Shaw R (2009) Virtual worlds in health care higher education. J Virtual Worlds Res 2:3-12

Jones D (2011) An alternative (to) reality. In: Researching learning in immersive virtual environments conference. The Open University Press, MK

Khan A, Lindquist K (2002) Blended learning at a Leading Education Institute: State of Practice. eLearn 2002

Levesque J, Lelievre E (2011) Creation and communication in virtual worlds. In: Experimentations with OpenSim. In: Richir S, Shirai A (eds) Virtual reality international conference-Laval virtual, Laval, France

Miller A, Allison C, McCaffery J, Sturgeon T, Nicoll J, Getchell K, Perera GIUS, Oliver I (2010) Virtual worlds for computer science education. In: Proceedings of the 11th annual conference of the higher education academy: subject centre for information and computer sciences, Durham, UK, pp 239-244

Minocha S, Tingle R (2008) Socialisation and collaborative learning of distance learners in 3D virtual worlds. In: Researching learning in virtual environments international. The Open University Press, MK, pp 216-227

Schrader PG (2008) Learning in technology: reconceptualising immersive environments. Assoc Adv Comput Educ J 16(4):457-475

Sharpe R, Benfield G, Roberts G, Francis R (2006) The undergraduate experience of blended e-learning: a review of UK literature and practice. The Higher Education Academy, London
Shukla M, Conrad M (2011) Second life is not an Island. In: Proceedings of the IADIS International Conference on e-Society. Avila, Spain, 10-13 March 2011

Singh H, Reed C, Software C (2001) A white paper: achieving success with blended learning. Centra Software 12

Steuer J (1992) Defining virtual reality: dimensions determining telepresence. J Commun 42:73-93

Strauss AL, Corbin MJ (1998) Basics of qualitative research: techniques and procedures for developing grounded theory, 2nd edn. Sage Publications, London

Vosinakis S, Koutsabasis P, Zaharias P (2011) An exploratory study of problem-based learning in virtual worlds. In: 3rd International conference on games and virtual worlds for serious applications (VS-Games), IEEE, Athens, Greece, pp 112-119

Vygotsky LS (1978) Mind society: the development of higher mental processes. Harvard University Press, Cambridge

Williams C (2002) Learning on-line: a review of recent literature in a rapidly expanding field. J Further Higher Educ 26:263-272

Zhao H, Sun B, Wu H, Hu X (2010) Study on building a 3D interactive virtual learning environment based on OpenSim platform. In: International conference on audio, language and image processing (ALIP), IEEE, Shanghai, China, pp 1407-1411 